\title{
Sounds, Signs and Hearing: Towards a Semiotics of the Audible Field
}

\author{
By Ivan Capeller*
}

\begin{abstract}
In what ways does the study of sounds allow for a revisiting of questions regarding Peirce's (1975) semiotics and its implications for the philosophy of language? This essay is an attempt to rethink the relationship between mimesis and semiosis through a research on how the process of hearing relates to sounds and meaning. To draw a map of what we call an audible field, Peirce's triadic logic is used to obtain a double articulation of Jacques Rancière's threefold method of distributing the sensible (ethical, poetical and aesthetical) with Michel Chion's three ways of hearing (reduced, causal, semantical). Peirce's three logical categories (firstness, secondness and thirdness) enables a number of triadic combinations between Chion's three ways of hearing, Rancière's threefold way of distributing the sensible and Peirce's own triadic ontology of the sign. These combinations allow the audible field to unfold according to the following partition: reduction to the ethical dimension of a strict regulation of its own volume and pitch variations; representation according to mimetical criteria of causal attribution of sounds to its supposed sources; and linearization into a signifying sequence of organized coded sounds. The final result is a semiotic understanding of the audible field as an organized gap between sounds and signs, a gap that can be rendered only through a positional diagram displaying the conceptual criss-crossing between Chion's and Rancière's triads, when these are simultaneously applied to sounds and hearing. The resulting diagram of the audible field shows how human hearing articulates itself with any kind of language around specific sound objects - such as human voices and musical patterns.
\end{abstract}

Keywords: Hearing, Aesthetics, Semiotics, Sounds, Signs

...ce seul objet dont le néant s'honore...

Mallarmé

\section{Introduction: Theory of Language and Audible Field}

The purpose of this essay is to rethink the relationship between the semiotic and the mimetic elements present in every language through a set of questions raised by what we call the audible field. What can the world of sounds and hearing tell us about the correlation between language's codification and semantization processes and the different social forms of seeing things and speaking about them?

The traditional duality established between the verbal and the visual fields not only silences the presence of sounds and the role of hearing in semiotic non-musical processes, but also overlooks completely the innumerable possibilities of inter-semiotic translation inherent to the verbal discourse's sphere, as well as to all kinds of sinesthesical phenomena in which words, images and sounds combine to provide some sort of (un)codified meaning.

These different possibilities of articulating meaning were already put forward by Walter Benjamin in two important (although relatively neglected) texts,

\footnotetext{
${ }^{*}$ Professor, School of Communication (ECO-UFRJ), Federal University of Rio de Janeiro, Brasil.
} 
respectively called Doctrine of the Similar and On the Mimetic Faculty. In a speculative attempt to discuss the general relationship between meaning and language, different modes of articulation between its mimetic and semiotic elements are to be considered, according to Benjamin: whenever we think about signs as mere arbitrary instruments of communication, we tend to repress the mimetic potential of language's sinesthesical faculties, since mimetic phenomena of correpondences and similarities (sensuous or nonsensuous alike) are probably at work in language's filo- and onto-genetic development in a much more powerful way than processes related primarily to a set of conventional signs. Thus, a radically anti-functionalist theory of language is deemed necessary in order to dislocate the conventional arbitrariness of the sign from its usual structuring linguistic function:

(...) If language, as is evident, is not an agreed upon system of signs, we will be constantly obliged to have recourse to the kind of thoughts that appear in their rawest, most primitive form as the onomatopoetic mode of explanation. (...) The key which finally makes this thesis fully transparent lies concealed in the concept of a nonsensuous similarity. For if words meaning the same thing in different languages are arranged about that signified as their center, we have to inquire how they all - while often possessing not the slightest similarity to one another are similar to the signified at their center (Benjamin 2005a: 696).

The Benjaminian doctrine of nonsensuous similarities, as opposed to the epistemic emphasis in the paradigmatical synchronic aspects that structure verbal languages, points rather to the syntagmatic dyachronical dimension of language as a sinesthesical process. In this process, the mimetic production of correspondences does not only represent a specific type of articulation between a signifier and a signified - as in the onomatopoeia cases - but the incessant reshaping of three possible opposite conceptual pairs that criss-cross all language(s) in themselves and in between them all, that is, as well in an intraas in an inter-semiotical axis of translation:

It is thus nonsensuous similarity that establishes the ties not only between what is said and what is meant, but also between what is written and what is meant, and equally between the spoken and the written. And every time, it does so in a completely new, original, and underivable way. The most important of these ties may, however, be the one mentioned last - that between what is written and what is said. For the similarity which reigns here is comparatively the most nonsensuous. It is also the one which takes the longest to be reached (Benjamin 2005a: 696697).

Turning a meaningful intention into its respective forms of expression, oral or written, alters the threshold between thoughts, words and images. Between concrete, sensuous correspondences and abstract symbolic conventions, images and sounds are able to establish with ideas different relations based on correspondences and nonsensuous analogies that precipitate into oral sayings, as well as into the visuality of written signs. Phonology and graphology may 
thus be thought of, as diachronical studies of the stratta deposited throughout the centuries into language by analogical ways of thinking (Haller-Roazez 2010):

Graphology has taught us to recognize in handwriting images that the unconscious of the writer conceals in it. It may be supposed that the mimetic process which expresses itself in this way in the activity of the writer was, in the very distant times in which script originated, of utmost importance for writing. Script has thus become, like language, an archive of nonsensuous similarities, of nonsensuous correspondences. But this aspect of language, as well as of script, does not develop in isolation from its other, semiotic aspect. Rather, the mimetic element in language can, like a flame, manifest itself only through a kind of bearer. This bearer is the semiotic element. Thus, the nexus of meaning of words or sentences is the bearer through which, like a flash, similarity appears. For its production by man - like its perception by him - is in many cases, and particularly the most important, tied to its flashing up. It flits past. It is not improbable that the rapidity of writing and reading heightens the fusion of the semiotic and the mimetic in the sphere of language (Benjamin 2005b: 722).

And in a brief appendix to the Doctrine of the Similar, Benjamin warns us to the fact that:

Our gift for seeing similarity is nothing but a weak rudiment of the once powerful compulsion to become similar and also to behave mimetically. And the lost faculty of becoming similar extended far beyond the narrow perceptual world in which we are still capable of seeing similarities (Benjamin 2005a: 698).

Benjamin unfolds a large overview of the relationship between language and history in which the mimetic properties of language seem to be gradually overwhelmed by its "communicational" semiotic functions; on the other hand, the formal aspects of a given language - heretofore to be understood as its "code" - become preponderant. Nevertheless, although consecrated by the cultural hegemony and epistemological primacy of the verbal languages, the binary polarization between the oral and the written modes of expression hides the fact that this opposition is the intra-semiotic equivalent of an inter-semiotic opposition of a wider spectrum. This is so because the written and the oral are both verbally codified forms of articulating audible and visible signifiers into verbal statements. There are, however, forms of meaning that are able to reshape the many different possible correspondences between these three fields of expression. This may occur without necessarily crystallizing and fossilizing the mimetic analogical processes at work in sedimented layers of symbolical conventions organized into linguistic stratta, composed by a certain mixture of statements and visibilities.

Hence, we require a renewed concept of language capable not only of expanding its investigative scope towards non-verbal codes, but also of digging the conceptual duality between words and images in order to unveil the audible field as the excluded third of the sign's double articulation postulated by Saussure (acoustic image + idea). Thus, behind the linguistic diad of the spoken and the written signs in which thought paradigms must codifiy visible and speakable 
syntagms, emerges a semiotical triad that intertwines sinesthesically the audible to the visible and to the speakable. Images, words and sounds establish between themselves a series of mimetical correspondences, sensuous or nonsensuous, motivated or not, that belong to pre-signifying, counter-signifying or postsignifying stratta of meaningful articulations. Such correspondences may cause shakedowns and "sismical" perturbations in the relative stability of the more superficial layers of discoursive enunciation.

Beyond the specific importance attached in this theoretical perpsective to so-called sound studies and to semiotical research on the audible field, it is also important to highlight the inevitable passage from a binary logic, based on the verbal model of double articulation, to a trinitary logic that multiplies the possibilities of a double articulation of words to images (and vice-versa) and words to sounds (and vice-versa), as well as sounds to images and vice-versa. In so doing, it introduces them all to an incessant movement of syntagmatic reshaping of meaning. This is not entirely strange to the peircean conception of a semiotics considered as a noetics, which is conceived as a logical process in which thought is able to shape and reshape the very fabric of representations that determines its own objects in a continuous movement, criss-crossing and crossfading intra and inter-semiotically all signs, languages and codes.

Benjamin's theory of language is akin to Peirce's triadic conception of the sign in a very specific way. His doctrine of the similar pressuposes the same possibility of a continuous analogical kinesthetic and sinesthesical passage between different fields of expression, linguistic codes and specific signs. Crossing these boundaries, according to Benjamin, implies a material, mimetic process subject to multiple meaning possibilities determined by a floating association of ideas. On the other hand, according to Peirce, a typology of signifying functions must be the result of a logical deduction, due to the iteration between the phenomenological categories of experience (firstness, secondness, thirdness) and the conceptual categories at work in the signifying process (representâmen, object, interpretant). The signifying process in itself is thought of as a continuous passage, following a tight semio-logical path, from more or less vague pre-signifying possibilities of articulation (hipossemes) to the establishment of a polissemic hermeneutical circuit of statements and assertives more or less adequate to their object(s). Thus, imitation by mimetic correspondence apparently finds itself regulated in a generative sign system that is no less based on the primacy of the verbal modes of enunciation over other visual and auditive modes of expression than other comparable semiological models.

Applying Peirce's semio-logics of thought to the audible field will enable us to rethink the tension pointed out by Benjamin between the mimetic and the semiotic elements of any language or code, inasmuch as this tension is not plainly thinkable just inside each and any verbal language individually considered or even, inter-semiotically speaking, just between the order of verbal statements and the order of the visual images.

The audible field, compared to the visual and the verbal fields, is considered a less reliable and more unstable field of codified meaning. Its gaps and fissures 
reveal more easily the inherent dichotomy or tension belonging to the very fabric of human language. This is all the more true when they have been mapped with rigourous semio-logical peircean parameters. Of all these gaps and fissures, the one capable of splitting our modes of hearing in a three-way partition that presides over our most basic and common auditory performances should be the object of more considered attention from all language and communications researchers.

\section{Threefold Hearing and the Audible Field}

The Brazilian semiotician Lucia Santaella has already highlighted the correspondence between the three Peircean phenomenological categories of experience and the three modes of hearing postulated by Michel Chion (2005) in his work L'Audio-Vision:

Michel Chion (...) has established three different modes of hearing that relate to different objects: causal hearing, semantical hearing and reduced hearing. As their correspondence to the peircean categories is strikingly obvious (...) I'll change its order to (1) reduced hearing, (2) causal hearing and (3) semantical hearing. (...) Chion (...) establishes a triad that, although not directly based on Peirce, presentes a perfect correspondence with his categories if we take the listener's behaviour, during the act of hearing, as the sole axis of classification (Santaella 2005: 85-86). ${ }^{1}$

Although there are many other typologies of the audible field, based on hearing and listening processes and intrinsic features of sounds, the typology developed by Chion has the advantage of avoiding the subordination of hearing and of the audible field to cognitivistic epistemical criteria. These have tended to classify the audible field in terms of a greater or lesser organizational complexity of sounds - considered by themselves - or of hearing considered in its greater or lesser capacity as an emotive, energetic or intellectual interpretant of sounds. Too bound to symbolic conventionalism understood as the structure of any codification process, these criteria cast over the audible field the same repressive attitude towards the sinesthesic-mimetical faculties of language already pinpointed by Benjamin regarding other forms and fields of semiotic expression.

In the specific case of the audible field, music is the privileged form of a would-be linguistical paradigm (or third order legi-sign, in Peircean terms) for all cultural configurations of the audible field. It is, nevertheless, a most problematic solution when compared to other linguistic and semiotic paradigms in charge of regulating the edge between what is to be seen and what is to be spoken. Music is the kind of sinesthesic, mimetic expression par excellence, based on the acoustic materiality of the sympathic resonance phenomenon and on the Peircean firstness with its emotive effects and iconic allures. Not by chance, the history of music presents a great number of anachronisms regarding

\footnotetext{
${ }^{1}$ The translation from the portuguese original version is mine.
} 
the history of literature and of the arts, both aesthetically and semiologically, since music was the last of the classical arts to be fully codified and regulated by an ideal poetics of artistic representation ${ }^{2}$. Furthermore, it is the one area in which this process was never entirely realized, especially regarding the polemical field of musical semantics.

Why is the audible field unable to organize itself, semiotically speaking, with the same precision and structural coherence easily verifiable for the visual and verbal fields? The audible field, even when it is doubly articulated by a musical code, is kinesthetically and sinesthesically covered up by a plethora of verbally regulated statements and socially controlled visibilities that erase almost completely the possibility of an autonomous thirdness (expressed in the artistical perspective of "pure music") - almost always already captured by orality (articulated speech, singing and lyrical voices), as well as by the visible field whenever a voice is attributed to a body and/or synchronized to it through movement, rhythm or dance.

However, between statements and visibilities, a semiotics of the audible field can be reasonably articulated through an expanded concept of music, conceived as a paradigm for different methods of third-order autonomous organizations of sounds. It is a clever solution, extremely helpful in demonstrating how the history of modern music (starting to unfold from the late 19th century tonal system dissolution) points to a neat reduction of its audible structures into hyposemic configurations of the second and first orders. As a result, a rigourous application of Peirce's semio-logical principles should be able to demonstrate (through logical deduction) the possibility of extracting and locating - in an expanded, but still musically oriented, audible field - all kinds of musical and non-musical sound structures composed or proposed by the great exponentes of concrete, electronic and eletcroacoustical music (Santaella 2005: 97-184).

On the other hand, the already mentioned correspondence between Peirce's three phenomenological categories of experience and Chion's three modes of hearing allows for a semiotics of the audible field that does not exclude musically organized sounds without positing them as the necessarily universal, supreme and final interpretants of the audible field. Reduced hearing may bring to our minds some sounds and structures musically thought of by Xenakis or John Cage. However, it may also be used as a movie production's sound mixer working technique or pertain to situations where we cannot identify and locate the sounds surrounding us or distinguish real or imaginary characteristics of sources. Causal hearing may refer us directly to certain musical instruments or to a singer's voice, but it also helps us identify day-to-day noises or ordinary people's voices on the telephone. Semantical hearing may concern auditory abilities capable of understanding very complex musical structures, but it also refers to orality and the central role played by verbal organized speech in all human societies.

\footnotetext{
${ }^{2}$ For example, the presence of the baroque Kapelmeister J. S. Bach during the first half of the classicist 18th century or the presence of the ultra-romantic Wagner throughout the whole impressionist and naturalist artistic trends of the final 19th century (Carpeaux 1967: 85).
} 
Even more important is the fact that the three-way division of the audible field by three modes of hearing reveals, inside the audible field, the same repressive processes posited by Benjamin's Doctrine of the Similar. Only reduced hearing would be able to unveil firstness's audible primacy as such, since causal hearing is pervaded by an indexical secondness related to what is already presentable as a visible object, whilst semantical hearing is inextricably bound up to thirdness-related symbolically structured sounds (like a set of verbal phonemes or of musical notes and chords). These sounds act as signifiers tied together to a chain of audible enunciations organized into verbal discourses or into musical syntagma.

Therefore, the audible field finds itself fissured into three distinct possibilities of organizing the experience of sounds correlated to the three Peircean categories of phenomenological experience. Thirdness is correlated to a semantical hearing capable of activating the required interpretants for a verbal or musical auditive message. Secondness relates to causal hearing inasmuch as sounds can act as traces or indexical marks of the supposed presence of real or imaginary sources or objects, whether visible or not. Firstness correlates to a special mode of hearing in which the listener's attention is reduced to following the free floating amplitude and frequency variations of sounds (its representamens) in their random modulation and environmental propagation.

\section{Semiotics of the Audible Field}

The correspondence between Chion's three modes of hearing and Peirce's three categories shapes a semiotics of the audible field that allows for an understanding of the way the generative component of verbal language covers up this field almost entirely through the invocation of semantical hearing. Nonetheless, the audible field presents a high rate of semiotic instability and a sinesthesical mimetic potential capable of acquiring unpredictable counter or post-significant properties. That is why the everlasting fissures of the audible field better reveal the constitutional tension between the mimetical and the semiotical elements inside any language. Even a semiotics understood as a noetics will not lead to a comprehensive overview of all morphological aspects of the audible field that would allow for a complete map of the main lines criss-crossing many stratta and multiple layers of expressive articulation. When it does not find itself completely tied to orality and verbal meaning, or to the visual field through different synchronical effects, the audible field is the most resilient counter-significant factor of cognitive disruption. A cry is always a condemnation of articulated reasonable speech and a dissonance can always be heard as an open stance against musical harmony, while noises are often posited as the last desperate possible opposition to a disquieting silence. Thus, the formulation of a theory of language articulated to the audible field must rely upon a theory of mimêsis understood not only as a supplementary element of meaning, but also as a social process that calls for a cultural and political regulation on a supra-semiotic level of analysis. We find the principles of such 
a theory in the threefold distribution of the sensible conceptualized on Jacques Rancière's Politics of Aesthetics. Despite his traditional emphasis on the visual and verbal aspects of the arts and dimensions of language, the audible field can be constantly eavesdropped upon in Rancière's three modes of distribution of the sensible. This occurs under the form of a contradiction: unpredictable bodily sounds (moaning, crying, sighing ...) are generally considered noisy destroyers of the rational order brought in by articulated speech through words (and regulated by the arts of oratory and rethoric), but when inscribed in a choreographical collective social order, organized sounds are able to synchronize the citizen's body to the Polis' rule and offer a political and cultural alternative to theatrical mimicry and its simulacra ${ }^{3}$.

Considering the mimetical phenomenon as a social and political problem, there must be a distribution of the audible, which is necessarily correlated to the distribution of the visual and the verbal. This is because the three distinct modes of organizing and distributing the sensible - the ethical, the poeticmimetical and the aesthetical - are bound to the fact that mimetical instability is not easily controllable by any kind of aesthetical or semiotic codification:

Mimêsis is not the law that brings the arts under the yoke of resemblance. It is first of all a fold in the distribution of ways of doing and making as well as in social occupations, a fold that renders the arts visible. It is not an artistic process but a regime of visibility regarding the arts. A regime of visibility is at once what renders the arts autonomous and also what links this autonomy to a general order of occupations and ways of doing and making (Rancière 2004: 22).

The concept of mimêsis thus considered, the problem of a potential spreading of politically uncontrollable "noisy" statements through the audible field may imply onto-political questions much more dangerous than the ones generally proposed, regarding the greater or lesser cognitive trustworthiness of words and images. However, the late cultural hegemony of music - considered as an ideal model for a semiotic-cognitive organization of the world of sounds nonetheless, is always a major recurrent problem to many different attempts to sketch a semiotics of the audible field.

That is why music's notorious delay, regarding the history of literature and the plastic arts, in producing a poetic code capable of regulating its sinesthesicmimetical expressiveness (a goal that was achieved only with the tonal theory of harmonics, at the begininning of the 18th century) escapes entirely Rancière's analytical scope when dealing with the constitution of the 17th century's poetic-mimetical arts regime. However, the discrepancies and anachronisms that permeate the history of music, when analysed through the audible fissures unveiled by a threefold partition of hearing, offer precious evidence about the relationship between the mimetic and the semiotic elements - not only for the audible field, but also regarding language itself.

\footnotetext{
${ }^{3}$ Gustavo Celedón (2015) has already pointed out the close relationship between Rancière's philosophy of aesthetics and some questions regarding the audible field and the so-called sound studies.
} 
In any case, Rancière's solution for the onto-political problem of the social status of the work of art, understood as a specific type of codified regulation of mimetical phenomena, demonstrates the continuous and recurrent character of his logic. From social and religious restraint (ethical regime) to representational codification (poetical-mimetical regime) and cultural dissemination (aesthetical regime), all verbal statements and visual representations are to be regulated and controlled not only as sensible (and sensuous) material messages striving to be heard and seen, but first and foremost as meaningful ideas urging to become effective thoughts: "a mode of articulation between ways of doing and making, their corresponding forms of visibility, and possible ways of thinking about their relationships (which pressuposes a certain idea of thought effectivity)" (Rancière 2004: 10).

This solution is akin to Peirce's triadical logic in its ordinal, recursive and inclusive character. This does not mean, however, that establishing correspondences and similarities between a semiotics understood as a noetics and the threefold way of distributing the sensible must imply a circular demonstration of a supposed conceptual identity between semiotical thought and aesthetical theory. This way of thinking would lead precisely to a theoretical mirroring of the repressive processes at work over the mimetical aspects of language - so dear to the aesthetical reflexion - by language's most prominent semiotical aspects. As a result of the inherent tension between the mimetical and the semiotical in every language-related phenomenon, possible correspondences (sensuous and nonsensuous) between Peirce's, Chion's and Rancière's triads will not necessarily determine identities of form and/or contents between the elements pertaining to each one of them. There are only serial isomorphy and structural homology, because the isomorphic structures belonging to the meaning generative processes can reveal similarities and differences between the audible, visual and verbal fields. This incessant shaping and reshaping of similarities and differences between these three fields happens through a certain movement traced by meaning around language (and by language around meaning) as a regular feature of language's transformational component and its pre-significant, counter-significant and post-significant instances.

In Chion's triad of the three modes of hearing, language is simultaneously the basis and the goal of all hearing activities, through a sort of cognitive circularity that allows for the extraordinary correspondence, highlighted by Santaella, with the Peircean phenomenological triad. This brings on a thorough description of the continuous possible shifting from hearing's pre-significant instances (phenomenological reduction of hearing, indexical causality suggested by the perception of sounds) to plainly meaningful and cognitive hearing instances (linguistical hearing and musical structure's hearing).

Rancière's triad of the distribution of sensible points in the opposite direction demonstrates the prominently ethical character of the pre-significant instances of the sensible - always in need of social control. Meanwhile he postulates the possibility of a second regime of sensible representations organized by one or more poetic-mimetical codes regulating both the order of statements (what is to 
be said or not) and the order of visibilities (what is to be seen or not). Thus, the theory corroborates Santaella's association between Peircean secondness and the indexical primacy of figurative images and of the visual field.

As for the way Rancière's aesthetical regime is intertwined with the Peircean concept of thirdness, we hit here the very core of Benjamin's assertion about how modern theories of language consummated the repression of language's constitutive mimetical element. Between the aesthetic and the semiotic, the resistance presented by the first to its entire absorption by the second (a crystal clear phenomenon when it comes to all known musical languages) simultaneously represents an advance and a withdrawal concerning language's cognitive ambitions. The withdrawal is expressed by its sheer resistance to a closed semantical structure, installing an open fissure between its form and its contents and exposing the materiality of its plan of expression as a void signifier; and the advance is seen inasmuch as this same resistance allows fast passage to an aesthetical, counter or post-significant regime in which the adequacy between the order of statements and the order of visibilities is no longer guaranteed by the traditional poetic-mimetical codes of representation. Therefore it is in need of incessant re-interpretation:

The aesthetic regime of the arts is the regime that strictly identifies art in the singular and frees it from any specific rule, from any hierarchy of the arts, subject matter and genre. Yet it does so by destroying the mimetic barrier that distinguished ways of doing and making affiliated with art from other ways of doing and making, a barrier that separated its rules from the order of social occupations. (...) The aesthetic state is a pure instance of suspension, a moment when form is experienced for itself. (...) The aesthetic regime of the arts, it can be said, is the true name for what is designated by the incoherent label "modernity" (Rancière 2004: 23-24).

This conception of a moderrn, aesthetical regime of distributing the sensible highlights its counter and post-significant aspects, bringing the self-reflexiveness characteristic of Peircean's thirdness closer to the open features of its transformational component in order to overcome the all-encompassing epistemological fantasy of a final interpretant of all language capable of closing in the universal semiotical process in an ultimate meaningful statement.

By criss-crossing Chion's three modes of hearing with Ranciére's three ways of distributing the sensible, we can deepen and amplify the mapping of the audible field already sketched above through Peirce's semiotics. Applying recursively Rancière's three régimes of distibuting the sensible to Chion's three modes of hearing in a conceptual cross-fade operated by Peirce's three phenomenological categories of experience, we have obtained a semiotical diagram of the fissures of the audible field that can be read either vertically, beginning with the three modes of hearing, or horizontally, through its three distinct audible regimes (Table 1). 
Table 1. Semiotics of the Audible Field

\begin{tabular}{|l|l|l|l|}
\hline $\begin{array}{l}\text { Audible } \\
\text { Regimes/ } \\
\begin{array}{l}\text { Modes of } \\
\text { Hearing }\end{array}\end{array}$ & \multicolumn{1}{|c|}{$\begin{array}{c}\text { Reduced hearing } \\
\text { Representamen }\end{array}$} & \multicolumn{1}{|c|}{$\begin{array}{c}\text { Causal hearing } \\
(2) \\
\text { Object }\end{array}$} & \multicolumn{1}{|c|}{$\begin{array}{c}\text { Semantical } \\
\text { hearing } \\
\text { In) } \\
\text { Interpretant }\end{array}$} \\
\hline $\begin{array}{l}\text { Ethical Regime } \\
\text { of modulation } \\
\text { and propagation } \\
\text { of sounds (1) }\end{array}$ & $\begin{array}{l}\text { Sound Objects: } \\
\text { Variations of } \\
\text { frequency, phase and } \\
\text { amplitude of sound } \\
\text { waves (concrete and } \\
\text { electroacoustic Music) }\end{array}$ & $\begin{array}{l}\text { Voice as Object: } \\
\text { Vocalization, } \\
\text { phonation, } \\
\text { intonation. } \\
\text { (phonoaudiology, } \\
\text { psychoanalysis) }\end{array}$ & $\begin{array}{l}\text { Modal music: } \\
\text { Noises, timbres, } \\
\text { languages } \\
\text { (Étiquette, } \\
\text { Sociology, } \\
\text { Anthropology) }\end{array}$ \\
\hline $\begin{array}{l}\text { Poetic- } \\
\text { Mimetical } \\
\text { Regime of } \\
\text { codification and } \\
\text { representation of } \\
\text { sounds (2) }\end{array}$ & $\begin{array}{l}\text { Audio Signals: } \\
\text { Recording, editing and } \\
\text { mixing sound tracks } \\
\text { (radio, cinema and } \\
\text { television) }\end{array}$ & $\begin{array}{l}\text { Voice as Chant: } \\
\text { Epics, lyrics, } \\
\text { dramatics (recitals, } \\
\text { poetics) }\end{array}$ & $\begin{array}{l}\text { Tonal music: } \\
\text { Genre, styles, } \\
\text { authors (rythm, } \\
\text { melody, harmony) }\end{array}$ \\
\hline $\begin{array}{l}\text { Aesthetical } \\
\text { Regime of } \\
\text { dissemination } \\
\text { and interpretation } \\
\text { of sounds (3) }\end{array}$ & $\begin{array}{l}\text { Sound Tracks: } \\
\text { Atmospheres, art } \\
\text { installations, sound } \\
\text { machines (sound } \\
\text { effects and sound } \\
\text { design) }\end{array}$ & $\begin{array}{l}\text { Diction, prosody } \\
\text { and accent } \\
\text { (linguistics, } \\
\text { elocutionary) }\end{array}$ & $\begin{array}{l}\text { Enunciation, } \\
\text { persuasion, } \\
\text { interpretation } \\
\text { (oratory, rethorics } \\
\text { and hermeneutics) }\end{array}$ \\
\hline
\end{tabular}

\section{Cries and Whispers}

In the present diagram of the audible field and its fissures, sound and language are articulated around voices, music and a variety of different types of noise that may emanate from a certain ambience - real or imaginary. That is the same threefold conception of the audible field commonly used for any movie sound mixing of its tracks, called by mixing engineers as $D, M \& E$ (Dialogue, Music \& Effects) (Forlenza and Stone 1993). This does not mean that sound for cinema techniques should necessarily be considered as a consolidated new paradigm capable of conceptualizing the audible field in such a satisfactory way that it could eventually replace musical paradigms. It means, rather, that sound for cinema, as well as the musical avant-garde movements of the 20th century, have not only explored the hypossemical limits of the audible field in its full Peircean sense, but have also presided over an unprecedented process of expansion and dilation of the audible field towards unsuspected aesthetical frontiers. While sound for cinema has built itself around the practice and experience of new possibilities of hearing, the avant-garde musical theory provided the concepts related to this expansion of the audible field, allowing it to be mapped by applying a simultaneously semiotical and aesthetical approach.

The most basic layer of reduced hearing is referred to as an ethics of modulation and propagation of sounds that encompasses apparently distinct problems and phenomena - from the laws against excessive noise ambience to problems concerning the common right to free public speech. Reduced hearing 
is the result of a phenomenological reduction of the audible field to its own variations of wave amplitude, frequency and phase, as perceived by a human ear as volume, pitch and placement (spatial localization) informations, in a presignificant layer of sound-objects that, considered as pure quali-signs, were uncovered and charted by last century's concrete and electroacoustic musical researches.

Audio signals are sound representamens deprived of any codified formal relationship between themselves. As sin-signs, they already lead the audible field towards secondness, in as much as reproduced sounds are always experienced as imaginary doubles indicating a correlated supposed real source or cause. Their particular potential for noise and nuisance (based on its electrical amplification through public speakers) calls for codified practices of modulation, broadcasting and amplified sound reproduction, and its possible interpretants are the physical properties of a sound considered in itself: frequency and wave lenght (emotive interpretant), volume sensation and relative sound intensity (energetic interpretant), and its own waveforms analysed as such (intelectual interpretant).

The art of shaping and reshaping sounds through analogic and digital audio signals came to be known in cinema circles as Sound Design. Although partial and limited, the possibilities of aestheticized reduced hearing, related to the meaningful semiotic functions of Peircean thirdness, are linked to auxiliary signifying roles of high mimetic expressiveness and efficacy played by certain sounds, be them musical or not, in a huge variety of narrative genres and/or staged shows. For instance, theatrical plays, movies and animated cartoons tend to offer a wide range of articulated sound effects (from Foley sounds of an almost graphic character to incidental soundtracks, ambiances and sound atmospheres or soundscapes) that are not organized and presented as an autonomous code of representation, but rather as auxiliary legi-signs that may be replicated to collaborate with signifying processes mainly conveyed by visual and verbal codes.

Nevertheless, for an expanded semiotics of the audible field, the most important feature commonly displayed by sound films is the need to synchronize sounding voices to a moving body or lip's image. Far from being only a technical trick or effect, lip-sync reveals the central role played by the voice as a privileged object of hearing. Voice is the causal object of human hearing par excellence, inasmuch as our own auditive physiology demonstrates that our ears were shaped (and sharply tuned in) to listen to the whole frequency range or spectrum of human voices in the most pitiful acoustic or otherwise perceptive conditions. Inside and outside the movies, voices are the most important object for the human hearing not only for the most obvious cognitive reasons related to the semantical hearing. Although causal hearing can be referred to an infinite number of possible sound objects, its main goal is to relate to a human voice in at least three different ways: iconic, indexical and symbolic.

Voice as an object is linked to pre-significant, ethical questions related to its iconic qualities. Its immediate objects refer to the flowing vocal variations 
(modulation, intonation, vocalization) studied by phonoaudiology. Silence as a sound object can be considered one of its most eloquent audible statements. Its dynamic objects belong to the realm of psychoanalysis and are of course in need of incessant interpretation. "Cries and Whispers" (as in the homonymous Ingmar Bergman movie) can be considered as iconical opposite signs that delineate the borders of this particular field of sound-objects.

Voice as chant is the most important sound-object regarding the relationship between voice and language. Precisely in-between the mimetical-expressive element of language and a fully codified semiotics, either musical and/or verbal, chant is probably the most universally stable sound-object of the audible field. There is no culture in which the vocal function is not strongly marked by sound indexes related to its timbre and tuning. In the intersection between causal hearing and the possible ways of poetically articulating sounds and voices into language and meaning, the complex phenomenon of orality arises precisely as ethno-musicological lyrics whose immediate object is the singing voice as a sinesthesical passage from the audible to the verbal that keeps a strong mimetical and imagetical expressive intensity. Its dynamic objects include the huge variety of lyrical and poetic methods of combining music and speech through verse. Aristotle's threefold division of the epic, the lyric and the dramatic forms of mimêsis is the first intellectual attempt to synthesise their possible interpretants into a unified systemical Poetics.

Voice as speech is the central object of causal hearing in its third symbolic layer. Its immediate object is language as such, considered as an abstract code, and its dynamic objects are the non-discoursive components of speech embedded in the sound materiality of voices. A less semantic and more aesthetic mode of hearing a speaking voice does not pay attention to the meaning of its discourse and its multiple possible interpretations. Rather, it focuses on its elocution, trying to situate on a socio-cultural level a given speech through its symbolic, linguistically organized, characteristics: its diction, prosody and accent.

Singing and speaking voices are sound-objects that reach the limits of the audible field to intermingle with the visual and verbal fields through language. Metaphors understood as poetic images, for example, are at the core of this process, since they are not generally pure visual or verbal forms of expression, spreading out mainly through oral (and audible) social resonance. However, the audible field is also capable of generating autonomous codes of expression, called in our culture "music". The concept of semantical hearing may thus cope with a semiology of music, as well as with a semiology of the verbal languages (or linguistics). Understood as "a pure combination of sounds", without any other reference to visual and/or verbal signs, music is an artistic discipline that is traditionally linked to the influx of a well established poetic-mimetical régime, under the influence of a highly semantical hearing.

The history of music shows the difficulty of the process of establishing an autonomous poetics of the audible field, for most of the so-called modal music is still comprised by a specific cultural ethics that provides the audible field its proper forms of expression, generally related to verbally transmitted myths and/or to 
gestually (and visually) performed rites. The iconical firstness that primarily informs this kind of music is of course what gives it its ethnic folklorical flavor, while its culturaly regulated ethics is what tends to maintain the audible field's strong mimetic sensory qualities in a state of permanent contention. Musical ideas, at this point, are only Peircean rhemas at the first cognitive stage of semantical hearing, still subordinated to a given set of verbal and visual expressions and having its interpretants outside the range of the audible field. A certain culture's étiquette and politeness rules may configure a first set of emotive interpretants of a given piece of music, such as its appropriateness for different social occasions, the type of emotions it should convey, the greater or lesser social prestige of a particular style of music in a specific society, etc. A second set of energetic interpretants would configure a whole sociology of a specific genre or kind of music, describing as completely as possible its sociocultural context, depicting its historical development, and stating its proper place in the history of music. Final interpretants would belong to a general anthropology of music, whose main three goals would be to provide a full overview of the history of all types of music, to formulate a general theory of sounds and music (as in Pierre Schaeffer's Traité des Objets Musicaux 1966) and to provide a closure of the audible field by stating its final interpretants.

The obvious impossibility of such a resolution of the audible field demonstrates, a contrario, the structural necessity of the fissures and anachronisms between the history of music and the history of literature and of the plastic arts. The last creation of the classical 17 th century poetic-mimetical régime, tonal music, is at the very edge of the aesthetical regime, and it is adequately situated at this intersection in our diagram. As an autonomous, self-referential system, it offers a representational image of a possible logical interpretant of the audible field and, as such, allows for a complete development of pure musical ideas as sound organized propositions or dici-signs. There is no doubt that, in pure musical terms, thirdness can be thought of as the triadic relationship between rhythm (1), melody (2) and harmony (3). These elements act recursively as music's own internal interpretants, unfolded into its emotive (rhythms), energetic (melodies) and intellectual ones (harmonies). Nevertheless, tonal music does not have to be considered in this diagram as the final and exclusive interpretant of Peircean's thirdness in the audible field.

Last but not least, semantical hearing's most celebrated cognitive achievement is our ability to follow oral discourse and listen to a given set of arguments. This is the most abstract and verbal spellbound layer of the audible field: oratory, rhetorics, and hermeneutics are related to its emotive, energetic and intellectual interpretants. Although highly regulated and controlled in its sinesthesical expressive capacity, the mimetic element of language often permeates verbal discourse through numberless correspondences - sensuous and nonsensuous - unforeseen by the code or language in use: homophones, puns, lapses, cacophonous sounds and undesirable rhymes unveil to us on a daily basis how language, amongst cries, whispers and arguments, resonates and amplifies the ever present fissure that is carved between sounds, signs and hearing. 


\section{Conclusion}

What does the diagram of the audible field tell us about the general relationship between language, sounds and images, as well as about the tension between the mimetical and the semiotical elements in every signifying process? While the first question raises a set of problems related to aesthetics understood as a theory of plastic arts and literary genre, the second one is primarily related to issues regarding the possibility of an epistemological paradigm capable of providing a conceptual synthesis between the theory of language and the theory of knowledge. In the short scope of this article, we were able only to hint at some preliminary hypotheses concerning these two questions.

For the aesthetical research in general, the main improvement brought up by a semiotics of the audible field is the conceptual dislocation of the traditional duality between the verbal and the visual fields of expression and its no less traditional description as a pair of complemetary opposite (convergent or divergent) poles. Unveiling the audible field as the excluded third of the verbal and the visual fields - a theoretical possibility unforeseen by Rancière's aesthetics - allows the crossfading and criss-crossing of all kinds of poetical genre codifications and stylistic models based on a supposed matricial primacy of the verbal codes over the visual ones (or vice-versa). This points towards a better understanding of the sinesthesical processes at work in the phenomenon of language from its very start, thus establishing the conceptual foundations for an all-encompassing aesthetical paradigm based on the primacy of mimetic material hybridizations over its subsequent decanting and distillation into poetically codified particular forms of art and expression.

This hypothesis of a primacy of the mimetic element of language over its properly semiotic element can also lead to a complete reshaping of our epistemological prejudices about the relationship between language and thought. Through a semiotical mapping of the audible field, it gets easier to demonstrate how verbal and musical third-order symbolical codes may arise from the more fluid and sensuous second and first-order signifying articulations already at work when voices and sound objects happen to be heard. The great scientific challenge of finding a conceptual ground to deal with the diachronical problem of the origins and evolution of language, as well as with the systemic analysis of its synchronical structures, therefore can be solved only outside the realm of verbal grammar and structural or transformational linguistics. Its secret lies in kinesthetic and synesthesical layers of intra-semiotical hybridizations that can be historically traced and semiotically described only through a speculative grammar (as in Peirce's semiotics) capable of mapping all possible meaningful articulations between sounds, signs and images. 


\section{References}

Benjamin W (2005a) Doctrine of the Similar. In M W Jennings (eds.), Selected Writings Vol.2 (Part 2) 1931-1934. Harvard: Belknap Press, pp. 694-698.

Benjamin W (2005b) On the |Mimetic Faculty. In M W Jennings (eds.), Selected Writings Vol.2 (Part 2) 1931-1934. Harvard: Belknap Press, pp. 720-722.

Carpeaux OM (1967) Uma nova história da música (A new history of music). Rio de Janeiro: Livraria José Olympio Editora.

Celedón G (2015) Philosophie et expérimentatio sonore (Philosophy and sound experimentation). Paris: L'Harmattan.

Chion M (2005) L'Audio-Vision - son et image au cinema (Audio-Vision - sound and image in the cinema). Paris: Armand Collin.

Forlenza J, Stone T (1993) Sound for Picture - an inside look at audio production for film and television. Winona: Mixbooks.

Heller-Roazen D (2010) Ecolalias - sobre o esquecimento das línguas (Ecolalias about forgetting languages). Campinas: Ed. Unicamp.

Peirce Ch.S (1975) Semiótica e filosofia - textos escolhidos (Semiotics and philosophy - chosen texts). São Paulo: Ed. Cultrix.

Rancière J (2004) The Politics of Aesthetics - The Distribution of the Sensible. London: Continuum International Publishing Group.

Santaella L (2005) Matrizes da Linguagem e Pensamento - sonora, visual, verbal (Matrices of Language and Thought - sonorous, visual, verbal). São Paulo: Ed. Iluminuras.

Schaeffer P (1966) Traité des objets musicaux (Treaty of musical objects). Paris: Éd. du Seuil. 